\title{
Extrapulmonary manifestations of COVID-19 patient presenting with abdominal pain and skin lesions as primary symptoms
}

\author{
Abhishek Kumar*, Dinesh Prasad, Vishnu Gahlot \\ Department of General Surgery, Simmer hospital and medical college, Bombay market road, Surat, Gujarat, India
}

Received: 08 September 2020

Revised: 17 December 2020

Accepted: 24 December 2020

\section{*Correspondence:}

Dr. Abhishek Kumar,

E-mail: abhisonygmes03@gmail.com

Copyright: $\odot$ the author(s), publisher and licensee Medip Academy. This is an open-access article distributed under the terms of the Creative Commons Attribution Non-Commercial License, which permits unrestricted non-commercial use, distribution, and reproduction in any medium, provided the original work is properly cited.

\begin{abstract}
COVID-19 is basically a respiratory disease and pulmonary manifestations constitute main presentations of the disease however in some patients SARS-CoV-2 infection is not limited to the respiratory system and other organs can also be affected and may be the primary manifestations of the disease. Renal dysfunction, gastrointestinal complications, liver dysfunction, cardiac manifestations, neurological abnormalities, haematological and thrombotic manifestations are among the reported extrapulmonary features. Given that ACE2, the entry receptor for the causative coronavirus SARS$\mathrm{CoV}-2$, is expressed in multiple extrapulmonary tissues, direct viral tissue damage is a plausible mechanism of injury. In addition, endothelial damage and thrombo-inflammation, dysregulation of immune responses, and maladaptation of ACE2-related pathways might all contribute to these extrapulmonary manifestations of COVID-19. Considering the broad spectrum of clinical manifestations and the increasing worldwide burden of the disease, there is an urgent need to evaluate patients presenting with abdominal symptoms and skin lesions even without respiratory complaints to increase the diagnostic accuracy to detect COVID-19 and its complications in early stage. Our case report documents a patient who presented with abdominal symptoms and skin lesions whose RT-PCR was positive for COVID-19. It remains to be seen whether these patients will eventually develop respiratory symptoms. Further studies are needed to elaborate and confirm the causative relationship between SARS-CoV-2 and the reported extrapulmonary manifestations of COVID-19.
\end{abstract}

Keywords: COVID-19, Abdominal pain, Splenic infarction, Skin rashes

\section{INTRODUCTION}

SARS-CoV-2 manifestations in a symptomatic patient can be in the form of pneumonia, acute respiratory syndrome, and multiple organ dysfunction as well. ${ }^{1}$ Renal complications, gastrointestinal dysfunctions, endocrine system disorders, myocardial dysfunction and arrhythmia, neurological dysfunctions, dermatological symptoms, haematological manifestations, and thromboinflammation are among the reported extrapulmonary complications. Moreover, the presence of coagulopathy, excessive and dysregulated immune responses, and autoimmunity by COVID-19 patients is considerable. ${ }^{2}$
The pathogenesis of infection entails the entry of the virus via receptors on cells, principally angiotensin-converting enzyme 2 receptors. Direct virus damage coupled with indirect effects of viral infection including thromboinflammation, dysfunction of the immune system, and dysregulation of the renin-angiotensin system leads to multiple organ failure. ${ }^{3}$ This review outlines the extrapulmonary organ-specific complications and their pathophysiology and epidemiology.

\section{CASE REPORT}

A 45-year-old female presented to the emergency department of SMIMER hospital complaining of 
generalised abdominal pain and tenderness in right hypochondrium for 5 days, which was gradually progressive and worsened over the next two days. She denied complain of chest pain, shortness of breath, cough, and fever. Along with abdominal pain she had skin lesions (Figure 1) over left forearm. Vital signs were normal and blood tests were normal except for mild leucocytosis $\left(11.1 \times 10^{4}\right.$ cells per litre). The patient underwent a contrast enhanced computed tomography (CT) scan of the abdomen and pelvis, which showed partial celiac axis thrombosis (Figure 2) involving $2 \mathrm{~cm}$ long segment from origin and splenic infarction involving almost $70 \%$ spleen parenchyma (Figure 3) with ground-glass nodule in the right middle lobe of lung (Figure 4). Rapid antigen test for COVID-19 was done which was negative. Nasopharyngeal swab for COVID-19, which was positive on real-time reverse transcriptase polymerase chain reaction (rRT-PCR) nasopharyngeal swab. Blood investigations of the patient shows increased FDP, CRP, IL- 6 and D-dimer. Patient was transferred to COVID-19 care facility where injection ramdesivir was given for 5 days along with single dose of injection tocilizumab (Il-6 antagonist) to counteract the cytokine storm. analgesics was given to reduce abdominal pain along with $\mathrm{LMWH}$, aspirin and dabigatran to treat and prevent progression of thromboembolic events. Patient did not require oxygen support as spo2 was maintained at $98 \%$ at room air and normal ABGA. After 7 days from admission patient RTPCR was repeated which was negative and no evidence of ground glass appearance on the repeat HRCT scan of lung but splenic infarct and celiac artery thrombosis persisted with no further progression. Finally, patient was discharged with advice of home isolation for 14 days and regular follow up in OPD.

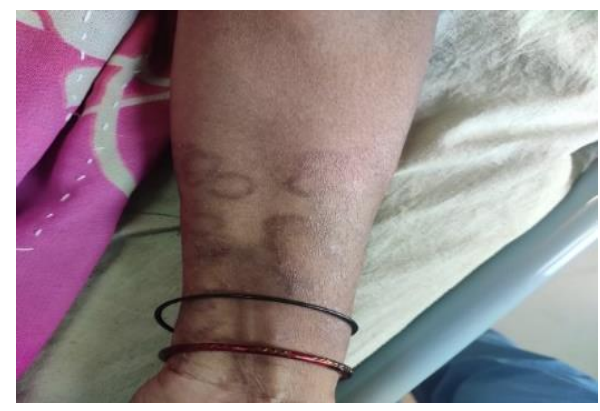

Figure 1: Skin lesion over forearm.

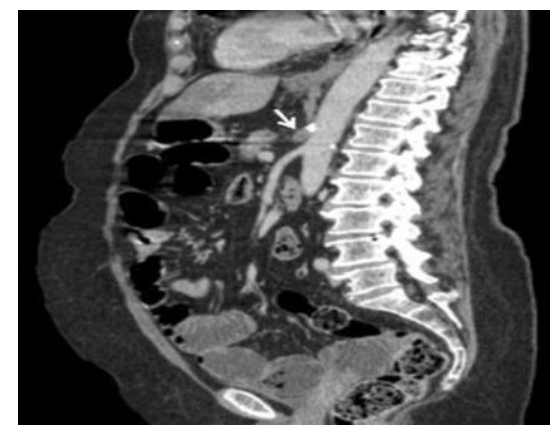

Figure 2: Celiac artery thrombosis.

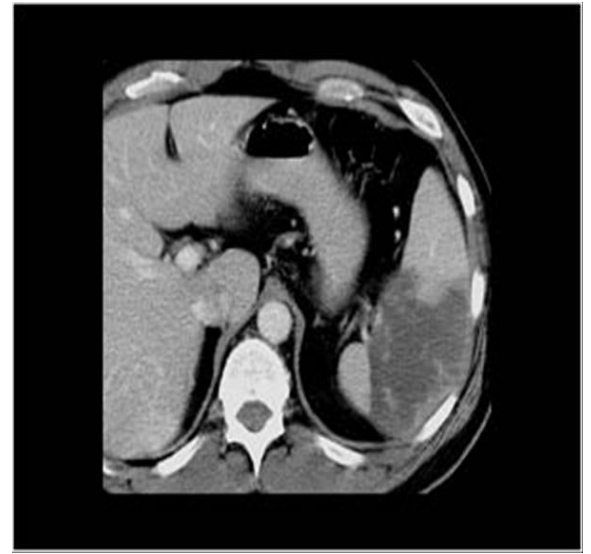

Figure 3: Splenic infaraction.

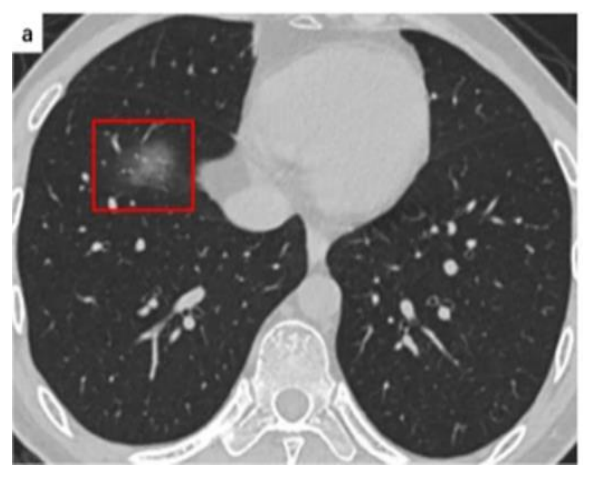

Figure 4: Ground glass opacity.

\section{DISCUSSION}

This case report describes a patient who presented to our health system with abdominal pain and erythematous lesions over the left forearm but without respiratory or thoracic symptoms, which, is an uncommon presentation of COVID-19 and prompted us to do CECT abdomen's abdomen which incidentally detected pulmonary findings, prompting RT-PCR testing for COVID-19 and patients subsequently tested positive. Non-productive cough, shortness of breath, and fever are the most common clinical presenting symptoms of patients with COVID$19 .^{4,5}$.

The SARS-CoV-2 virus utilizes the angiotensinconverting enzyme 2 receptor for entry into the host cell. These receptors are profusely expressed on lung tissues and arterial and venous endothelial cells. ${ }^{6}$

This cases principally highlights celiac artery partial thrombosis and splenic infarction $(70 \%)$ as a thrombotic complication of COVID-19 and probably the only reported case so far as per search in various medical journals and websites and this led to conclusions that although thrombotic events are one of the main complications of SARS-CoV-2 infection, reports and imaging findings of splenic infarction and celiac artery thrombosis are scarce in the literature. ${ }^{7}$ The incidence of splenic infarctions is probably underestimated as abdominal imaging is not 
routinely performed, and they are often incidental findings from chest CT scans that extend to the abdomen or in CECT abdomen. In the patients of severe COVID-19, coagulopathies are important detrimental factors that are invariably associated with poor outcomes. The hallmark coagulopathy abnormalities in COVID-19 are elevated prothrombin time, raised D-dimer level, raised IL-6 and these parameters were increased in our patients too.

Although the cutaneous manifestations of COVID-19 are infrequent, it is of great importance, as they may contribute to sooner and better diagnosis and management of the disease, even in asymptomatic or pauci symptomatic patients. $^{8}$ This could be a valuable help for epidemiological control of the disease. ${ }^{9}$

Although COVID-19 is a prolonged, complicated, and sometimes fatal disease, most of the patients are expected to eventually recover. Our patient was immediately transferred to fully functional and equipped COVID-19 patient care facility and was kept on analgesics to reduce abdominal pain. Patient was given LMWH, aspirin and dabigatran to treat and prevent progression of thromboembolic events.

\section{CONCLUSION}

In the current pandemic, clinicians should be aware of abdominal symptoms, cutaneous manifestations and thrombotic disease as a complication of COVID-19 and clinician should be cautious and keep COVID-19 as differentials diagnosis when encountered with extrapulmonary manifestations to facilitate early diagnosis of SARS COV-2. Moreover, lung findings in COVID-19 patients may not correlate to respiratory symptoms.

Further studies should be carried out to elucidate the pathophysiological mechanisms of COVID-19-related extrapulmonary manifestations, and so that early preventive and therapeutic strategies can be developed to reduce morbidity and mortality before vital organ damage.

Funding: No funding sources Conflict of interest: None declared

Ethical approval: Not required

\section{REFERENCES}

1. Voutsinas N, Toussie D, Jacobi A, Bernheim A, Chung M. Incidental CT findings in the lungs in COVID-19 patients presenting with abdominal pain. Clin Imaging. 2020;67:1-4.

2. Mao R, Qiu Y, He JS, Tan JY, Li XH, Liang J, et al. Manifestations and prognosis of gastrointestinal and liver involvement in patients with COVID-19: a systematic review and meta-analysis. Lancet Gastroenterol Hepatol. 2020;5(7):667-78.

3. Jin X, Lian JS, Hu JH, Gao J, Zheng L, Zhang YM, et al. Epidemiological, clinical and virological characteristics of 74 cases of coronavirus-infected disease 2019 (COVID-19) with gastrointestinal symptoms. Gut. 2020;69(6):1002-9.

4. Yang W, Cao Q, Qin L, Wang X, Cheng Z, Pan A, et al. Clinical characteristics and imaging manifestations of the 2019 novel coronavirus disease (COVID-19): A multi-center study in Wenzhou city, Zhejiang, China J Infect. 2020;80(4):388-93.

5. Del Rio C, Malani PN. COVID-19-New Insights on a Rapidly Changing Epidemic. J Am Med Assoc. 2020;323(14):1339-40.

6. Miri SM, Roozbeh F, Omranirad A, Alavian S M. Panic of Buying Toilet Papers: A Historical Memory or a Horrible Truth? Systematic Review of Gastrointestinal Manifestations of COVID-19, Hepat Mon. 2020;20(3):102729.

7. Santos M, Lima FC, Pimentel AC, Costa JC, Holanda JL. Multisystemic Infarctions in COVID-19: Focus on the Spleen. Eur J Case Rep Intern Med. 2020;7(7):001747.

8. Up To Date. Coronavirus disease 2019 (COVID-19): Cutaneous manifestations and issues related to dermatologic care. Available at: https://www.uptodate.com/contents/covid-19cutaneous-manifestations-and-issues-related-todermatologic-care. Accessed on 29 August 2020.

9. Usher AD. WHO launches crowdfund for COVID19 response. Lancet. 2020;395(10229):1024.

Cite this article as: Kumar A, Prasad D, Gahlot V. Extrapulmonary manifestations of COVID-19 patient presenting with abdominal pain and skin lesions as primary symptoms. Int Surg J 2021;8:1597-9. 